\title{
Influência da sacarose e do corte da base da haste na longevidade de inflorescências de Zinnia elegans ${ }^{(1)}$
}

\author{
Tânia Forster Carneiro(2), Fernando Luiz Finger ${ }^{(3)}$, Vanessa Rebouças dos Santos ${ }^{(2)}$, \\ Ludmila Lafetá de Melo Neves ${ }^{(2)}$ e José Geraldo Barbosa(3)
}

\begin{abstract}
Resumo - Flores de zínia (Zinnia elegans Jacq.) são adaptadas às condições climáticas da Região Sudeste do País, com excelente potencial para a comercialização como flor de corte. O presente trabalho objetivou avaliar a influência da sacarose aplicada na forma de solução de condicionamento, e do corte periódico da base das hastes sobre a longevidade e absorção de água pelas flores. Hastes florais uniformizadas em tamanho foram submetidas ao condicionamento, por seis horas, com sacarose a 5, 10, 15 e $20 \%$ ou com soluções de $10 \%$ de sacarose por $0,6,12$, 18 e 24 horas, com ou sem cortes periódicos na base das hastes a cada 48 horas. $\mathrm{O}$ tratamento das flores por seis horas com sacarose a 5, 10, 15 ou $20 \%$ não afetou a longevidade das flores, comparado àquelas mantidas somente com água destilada. $\mathrm{O}$ corte periódico da base das hastes promoveu melhor suprimento de água às flores, estendendo a longevidade. O condicionamento das flores com $10 \%$ de sacarose por 18 ou 24 horas acelerou a senescência das flores em vaso. A taxa de produção de etileno foi inibida pelo aumento da concentração de sacarose na solução de condicionamento.
\end{abstract}

Termos para indexação: Zinnia elegans, flor, etileno, absorção de água, senescência.

\section{Longevity of Zinnia elegans inflorescences affected by sucrose and recuts of the stem}

\begin{abstract}
Flowers of zinnia (Zinnia elegans Jacq.) are well adapted to the growing conditions of South-eastern Brazil, and have excellent potential to be commercialized as cut flower. This work aimed to evaluate the influence of sucrose, applied as pulsing solution, and the effect of periodical recuts on the stem base on the flowers longevity and flowers water uptake. Cut inflorescences with similar length were pulsed for six hours with $0,5,10,15$ and $20 \%$ sucrose or with $10 \%$ sucrose for $0,6,12,18$ and 24 hours, with or without recuts at stem base at every 48 hours. Treatments with 5, 10, 15 and $20 \%$ sucrose for six hours did not affect flower longevity compared to untreated flowers. Recuts on the stem base improved water uptake and extended the flower longevity. Pulsing the inflorescences with $10 \%$ sucrose for 18 or 24 hours hastened flower senescence in vase. Ethylene production was inhibited by increasing the concentration of sucrose in the pulsing solution.
\end{abstract}

Index terms: Zinnia elegans, flowers, ethylene, water uptake, senescence.

\section{Introdução}

A zínia (Zinnia elegans Jacq.) é uma planta herbácea anual, de pleno sol, pertencente à família Compositae, considerada como planta nativa das Américas (Sacalis, 1993) e popularmente conhecida

\footnotetext{
(1) Aceito para publicação em 21 de fevereiro de 2002.

(2) Universidade Federal de Viçosa (UFV), Dep. de Fisiologia Vegetal, CEP 36571-000 Viçosa, MG. E-mail: taniafoster@hotmail.com, vanessareb@bol.com.br, llafeta@alunos.ufv.br

(3) UFV, Dep. de Fitotecnia, CEP 36571-000 Viçosa, MG. E-mail: ffinger@ufv.br, jgeraldo@ufv.br
}

como capitão, moça e velha ou canela-de-velho e apresenta flores do tipo margarida simples, dobrado ou crespo (Lorenzi \& Souza, 1999) e de várias cores: branca, amarela, laranja, vermelha, rosa e púrpura (Fell, 1983). As zínias se propagam por semente, apresentam rápido crescimento e facilidade de cultivo (Stimart et al., 1983) durante a primavera e verão. Esta espécie é utilizada principalmente em paisagismo, como bordaduras e em maciços florais, porém suas hastes florais têm grande potencial de uso como flor de corte e, podem suprir o mercado como mais uma opção de produto fora de época, por ocasião do outono e inverno nos países do hemisfério norte. 
A senescência e o murchamento das flores ou inflorescências de corte podem estar associadas à redução da absorção de água pelas hastes. As obstruções dos vasos xilemáticos são de natureza fisiológica, ocorrem por embolia ou presença de microrganismos, especialmente bactérias que se multiplicam na parte basal das hastes (Sacalis, 1993; Williamson \& Milburn, 1995). Campanha et al. (1997) observaram que cortes periódicos da base das hastes de Strelitzia reginae resultam em maior absorção de água, hidratação das sépalas, e prolongam a vida em vaso das inflorescências. Em zínias, não há relatos sobre a influência de cortes periódicos da base das hastes sobre a absorção de água e longevidade das flores.

As flores em geral são classificadas como produtos altamente perecíveis, pela natureza efêmera dos diferentes tecidos que as formam, pela alta atividade respiratória e pelo reduzido conteúdo de carboidratos de reserva (Nowak \& Rudnicki, 1990). Assim, o suprimento adequado de carboidratos, em flores cortadas, além de fornecer energia para a manutenção da respiração vital, atua como regulador osmótico dos tecidos. O condicionamento das flores ou folhas ornamentais de corte pode ser definido como o tratamento utilizado nas primeiras 24 horas após a colheita, onde estas são saturadas com soluções contendo substâncias químicas, como açúcares, ácidos e inibidores da ação ou da síntese de etileno. Como o conteúdo de carboidratos de reserva em flores é limitado, geralmente a adição destes, principalmente na forma de sacarose, tanto em solução de condicionamento como em solução de vaso, é eficaz no aumento da longevidade de diversas espécies de flores de corte, como observado em flores de ervilha por Ichimura \& Hiraya (1999). O uso de sacarose em solução na forma de condicionamento prolonga a longevidade das flores de Gypsophila paniculata e Strelitzia reginae (Dows et al., 1988; Doorn \& Reid, 1992; Finger et al., 1999), porém o efeito de soluções de sacarose, tanto na forma de condicionamento como na forma de solução em vaso, pode variar consideravelmente entre as espécies.

Em diversas espécies ornamentais o etileno exerce importante papel na aceleração da senescência, resultando na deterioração dos tecidos e conseqüente redução da vida pós-colheita das flores (Abeles et al.,
1992). Em zínia, não há relatos da evolução de etileno durante o desenvolvimento da senescência das flores e da influência da sacarose sobre a produção deste hormônio.

Este trabalho objetivou avaliar a influência da sacarose aplicada na forma de solução de condicionamento e do corte periódico da base das hastes sobre a longevidade e a absorção de água pela flor.

\section{Material e Métodos}

Flores de zínia, cultivar Double Choice Mixed, foram colhidas do campo de cultivo do setor de Floricultura da Universidade Federal de Viçosa, (UFV), Viçosa, MG, pela manhã (7h), no ponto de colheita comercial, capítulo completamente aberto e foram transportadas imediatamente para o laboratório onde foram uniformizadas com aproximadamente $40 \mathrm{~cm}$ de comprimento, e divididas ao acaso, para os diferentes tratamentos. Os vasos permaneceram em temperatura de $25^{\circ} \mathrm{C}$, umidade relativa de $60 \%$ e intensidade luminosa de $10 \mu \mathrm{mol} \mathrm{m}^{-2} \mathrm{~s}^{-1}$. As flores testemunha foram mantidas em vasos contendo água destilada renovada a cada dois dias. A senescência e longevidade das flores foram avaliadas com base na escala descritiva da qualidade como segue: estádio 0 : excelente turgidez e rigidez da haste floral, capítulo aberto com pétalas com cor viva e brilhante, hastes e folhas com cor verde brilhante; estádio 1: boa turgidez e rigidez da haste floral, florescimento uniforme, boa coloração das pétalas; estádio 2: boa turgidez e rigidez da haste floral sem curvatura, início do murchamento ou clorose foliar, início da descoloração das pétalas; estádio 3: haste floral com curvatura, murchamento acentuado ou clorose foliar, descoloração das pétalas aparente. O estádio 3 define o término da longevidade da flor quando houve perda do valor ornamental e comercial.

As flores selecionadas foram tratadas com solução de condicionamento por seis horas com sacarose a $0,5,10,15$ e $20 \%$, ou por $6,12,18$ e 24 horas, com solução de sacarose a $10 \%$. Posteriormente, as flores foram transferidas para recipientes de $500 \mathrm{~mL}$ contendo água destilada, a qual foi renovada a cada dois dias. Diariamente foram realizadas análises do murchamento e senescência das flores e hastes, conforme a escala de notas descrita previamente. $\mathrm{Na}$ avaliação da influência dos cortes periódicos, na base das hastes, sobre a absorção de água e longevidade, as hastes foram cortadas a $2 \mathrm{~cm}$ da base a cada 12 ou 48 horas após a colheita, respectivamente. A estimativa da absorção de água pelas flores foi baseada nas alterações póscolheita do peso da matéria fresca das hastes, expressa em porcentual da matéria fresca inicial. 
A produção de etileno das flores tratadas por seis horas, com $0,5,10,15$ e $20 \%$ de sacarose, foi avaliada a cada dois dias. Capítulos foram destacados e colocados individualmente em frascos de $500 \mathrm{~mL}$ lacrados e, após oito horas de acúmulo, foram retiradas amostras de $1,0 \mathrm{~mL}$ da atmosfera dos frascos, com o auxílio de uma seringa hipodérmica. A seguir, avaliou-se concentração de etileno em cromatógrafo a gás equipado com detector de ionização de chama e coluna Porapak-Q.

Em cada experimento, foram utilizadas, no mínimo, 16 flores em quatro repetições. Os dados foram submetidos à análise de variância (ANOVA), as médias dos fatores qualitativos foram comparadas pelo teste $t$, e os fatores quantitativos, por análise de regressão.

\section{Resultados e Discussão}

A resposta das flores às concentrações das soluções de condicionamento com sacarose não diferiu significativamente do controle (Tabela 1). A longevidade média das flores de zínias foi de oito dias nos tratamentos de condicionamento com sacarose ou controle com água destilada, com 2,9 a 3,5 dias, no estádio de melhor qualidade visual (estádio 0). Woltering \& Doorn (1988) verificaram que o murchamento das flores foi o sintoma inicial de senescência em zínias, não havendo abscisão dos tecidos florais e folhas, semelhantemente aos sintomas observados no presente trabalho. Em todos os tratamentos foi observado o aparecimento de necrose na base das hastes e pétalas, e início de murchamento das hastes após o sexto dia da colheita. Ichimura \& Suto (1999) observaram que a sacarose aplicada na forma de solução de condicionamento ou em solu- ção de vaso reduziu a longevidade de flores de ervilha, causando rachaduras nas pétalas, decréscimo na absorção de água, e aumento da produção de etileno. Neste experimento a aplicação de sacarose não resultou na extensão da longevidade das flores da mesma forma que em orquídeas do gênero Oncidium (Young \& Ong, 1979), em ciclame (Kohl, 1975) e estátice (Doi \& Reid, 1995).

As hastes que receberam o corte na base apresentaram leve aumento da massa fresca até 44 horas após a colheita, seguido por um período de persistente decréscimo (Figura 1). Este aumento da matéria fresca inicial não diferiu significativamente em relação às hastes que não receberam cortes a cada 12 horas. As hastes que não receberam o corte na base apresentaram declínio contínuo da matéria fresca após a colheita e com taxa superior àquela observada nas hastes cortadas periodicamente (Figura 1). Stimart et al. (1983) trabalhando com flores de zínias, mantidas em soluções contendo carboidrato mais 8-citrato de hidroxiquinolina, observaram aumento da matéria fresca nos primeiros dias seguido de um decréscimo gradual. Evidenciou-se, assim, que as hastes que receberam o corte na base apresentaram, nos primeiros dias após a colheita, maior absorção de água pelas hastes e hidratação das flores, e aumento da capacidade de retenção de água pelos tecidos florais até a saturação, seguido por um período de decréscimo da massa fresca em virtude da senescência (Rogers, 1973).

A longevidade das flores que receberam cortes periódicos a cada dois dias na base foi superior à das hastes não-cortadas (Tabela 2). Hastes condi-

Tabela 1. Longevidade (dias) de flores de zínia (Zinnia elegans) em diversos estádios de senescência, após o condicionamento por seis horas em diferentes soluções de sacarose ${ }^{(1)}$.

\begin{tabular}{|c|c|c|c|c|c|}
\hline \multirow[t]{2}{*}{ Estádios de senescência ${ }^{(2)}$} & \multicolumn{5}{|c|}{ Sacarose $(\%)$} \\
\hline & 0 & 5 & 10 & 15 & 20 \\
\hline 0 & 3,5 & 3,2 & 3,2 & 2,9 & 3,4 \\
\hline 1 & 2,0 & 1,6 & 1,5 & 2,0 & 2,1 \\
\hline 2 & 1,6 & 1,5 & 1,4 & 1,8 & 1,6 \\
\hline 3 & 0,9 & 1,3 & 1,5 & 1,2 & 0,9 \\
\hline Longevidade total & $8,0 \mathrm{a}$ & $7,6 a$ & $7,6 a$ & $7,9 a$ & $8,0 \mathrm{a}$ \\
\hline
\end{tabular}


cionadas com sacarose a $10 \%$ por 6 ou 12 horas, e periodicamente cortadas, ou não, na base, não tiveram a vida de vaso prolongada em relação às mantidas somente em água destilada. A exposição das hastes a $10 \%$ de sacarose por 18 ou 24 horas reduziu a longevidade total, independentemente do

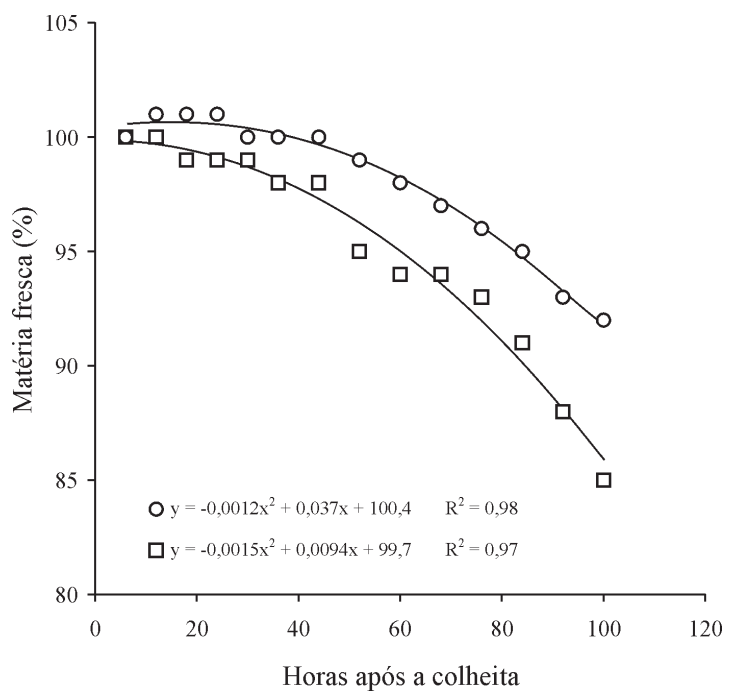

Figura 1. Porcentagem de matéria fresca em hastes de zínias (Zinnia elegans) cortadas (O) e não-cortadas ( $\square$ ) a cada 12 horas na base das hastes. fato de as flores serem cortadas, ou não, na base, a cada dois dias. Em ambos os tratamentos também houve redução do número de dias em que as flores apresentaram melhor qualidade visual (estádio 0) (Tabela 2). Provavelmente, em zínia, a exposição das hastes a soluções de sacarose a $10 \%$ por 18 ou 24 horas foi excessivamente longa, acelerando a deterioração das flores, ou nestas flores o suprimento de carboidratos não representa um fator limitante da longevidade de zínias em vaso. Markhart \& Harper (1995) observaram em rosas cv. Kardinal, que o tratamento contínuo das hastes com soluções preservativas contendo sacarose provocou o surgimento de lesões necróticas nas folhas, resultando em menor longevidade final das flores em vaso.

A taxa de produção de etileno das flores foi inibida pela sacarose nas concentrações de 10,15 e $20 \%$ ao longo da vida em vaso (Figura 2). Um dos efeitos benéficos da sacarose pode ser atribuído ao melhor equilíbrio das relações hídricas (Halevy \& Mayak, 1979) e ao atraso na indução da formação de etileno, como foi observado em flores de boca-de-leão, por Ichimura \& Hisamatsu (1999). Em zínias, a senescência das pétalas se caracterizou por murchamento lento após a colheita, sem significativa elevação na produção de etileno. Segundo Woltering \& Doorn (1988),

Tabela 2. Longevidade (dias) de flores de zínia (Zinnia elegans) submetidas a soluções de condicionamento com sacarose $10 \%$, por diferentes períodos, em razão dos estádios de senescência, nos tratamentos com ou sem corte na base das hastes ${ }^{(1)}$.

\begin{tabular}{|c|c|c|c|c|c|}
\hline \multirow[t]{2}{*}{ Tempo de condicionamento (horas) } & \multicolumn{5}{|c|}{ Estádios de senescência ${ }^{(2)}$} \\
\hline & 0 & 1 & 2 & 3 & Total \\
\hline & \multicolumn{5}{|c|}{ Sem corte das hastes } \\
\hline Testemunha & 4,0 & 2,5 & 1,0 & 1,0 & $8,5 b$ \\
\hline 6 & 4,8 & 2,0 & 0,7 & 1,0 & $8,5 b$ \\
\hline 12 & 4,8 & 1,5 & 1,0 & 0,6 & $7,9 \mathrm{bc}$ \\
\hline 18 & 3,8 & 2,0 & 0,3 & 1,0 & $7,1 \mathrm{c}$ \\
\hline \multirow[t]{2}{*}{24} & 3,0 & 1,3 & 1,0 & 1,0 & $6,3 \mathrm{~d}$ \\
\hline & \multicolumn{5}{|c|}{ Com corte das hastes } \\
\hline Testemunha & 4,8 & 2,0 & 1,2 & 1,0 & $9,0 \mathrm{a}$ \\
\hline 6 & 4,7 & 2,0 & 0,8 & 1,3 & $8,8 \mathrm{a}$ \\
\hline 12 & 5,3 & 1,5 & 1,0 & 1,0 & $8,8 \mathrm{a}$ \\
\hline 18 & 4,6 & 1,2 & 0,5 & 1,0 & $7,3 \mathrm{c}$ \\
\hline 24 & 4,7 & 1,3 & 0,7 & 0,3 & $7,0 \mathrm{c}$ \\
\hline
\end{tabular}

${ }^{(1)}$ Médias seguidas da mesma letra na coluna não diferem entre si pelo teste t a $5 \%$ de probabilidade. ${ }^{(2)} 0$ : excelente turgidez e rigidez da haste floral, capítulo aberto com pétalas com cor viva e brilhante, hastes e folhas com cor verde brilhante; 1: boa turgidez e rigidez da haste floral, florescimento uniforme, boa coloração das pétalas; 2: boa turgidez e rigidez da haste floral sem curvatura, início do murchamento ou clorose foliar, início da descoloração das pétalas; 3: haste floral com curvatura, murchamento acentuado ou clorose foliar, descoloração das pétalas aparente. 


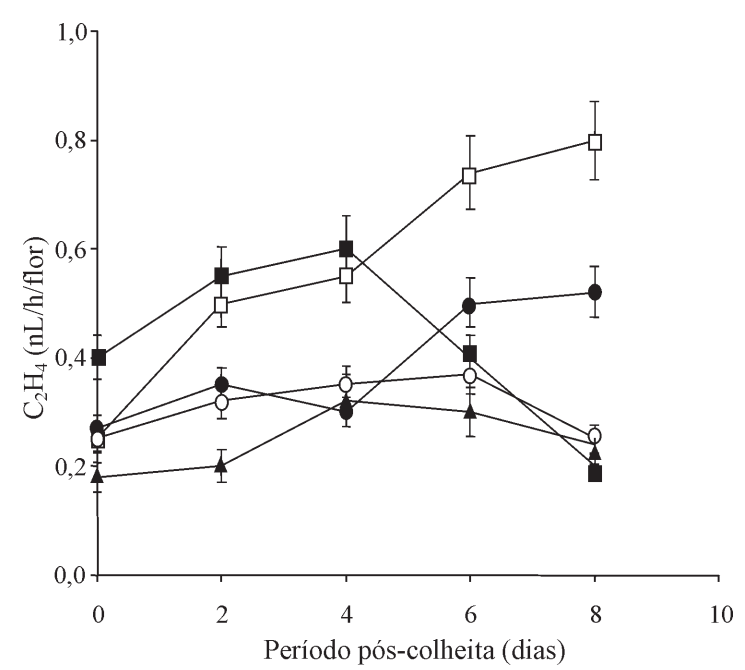

Figura 2. Produção de etileno por hora e por flor, em razão do período após a colheita (dias) de flores de zínia (Zinnia elegans) após condicionamento por seis horas com sacarose a $0(\square), 5(\square), 10(\bullet), 15$ (○) e 20\% ().

as cultivares de zínias em geral têm baixa sensibilidade ao etileno, evidenciando que a senescência parece não ser mediada pelo etileno.

\section{Conclusões}

1. As flores de zínias têm longevidade em vaso de aproximadamente oito dias, tendo, portanto, potencial para utilização como flor de vaso.

2. O condicionamento das flores com sacarose não resulta em aumento da longevidade das flores.

3. A aplicação de sacarose a $10 \%$ por 18 ou 24 horas reduz significativamente a vida em vaso.

4. O corte periódico da base das hastes foi efetivo na melhoria da hidratação das flores, resultando em maior longevidade.

5. A taxa de produção de etileno pela flor é inibida pelo aumento da concentração de sacarose na solução de condicionamento.

\section{Agradecimentos}

À Capes e ao CNPq, pela concessão das bolsas a Tânia F. Carneiro e Fernando L. Finger, respectivamente.

\section{Referências}

ABELES, F. B.; MORGAN, P. W.; SALTVEIT JUNIOR, M. E. Ethylene in plant biology. 2. ed. San Diego: Academic, 1992. $414 \mathrm{p}$.

CAMPANHA, M. M.; FINGER, F. L.; CECON, P. R.; BARBOSA J. G. Water relations of cut bird-of-paradise (Strelitzia reginae Ait.) inflorescences. Revista Brasileira de Horticultura Ornamental, Campinas, v. 3, n. 1, p. 27-31, 1997.

DOI, M.; REID, M. S. Sucrose improves the postharvest life of cut flowers of a hybrid Limonium. HortScience, Alexandria, v. 30, p. 1058-1060, 1995.

DOORN, W. G. van; REID, M. S. Role of ethylene in flower senescence of Gypsophila paniculata L. Postharvest Biology and Technology, Amsterdam, v. 1, p. 265-272, 1992.

DOWS, C. G.; REIHANA, M.; DICK, H. Bud opening treatments to improve Gypsophila quality after transport. Scientia Horticulturae, Oxford, v. 34, p. 301-310, 1988.

FELL, D. Gallery of garden annuals. Tucson: Fisher, 1983. $160 \mathrm{p}$.

FINGER, F. L.; CAMPANHA, M. M.; BARBOSA, J. G.; FONTES, P. C. R. Influence of ethephon, silver thiosulfate and sucrose pulsing on bird-of-paradise vase life. Revista Brasileira de Fisiologia Vegetal, Brasília, v. 11, n. 2, p. 119-122, 1999.

HALEVY, A. H.; MAYAK, S. Senescence and postharvest physiology of cut flowers: part 1. Horticultural Reviews, New York, v. 1, p. 79-80, 1979.

ICHIMURA, K.; HIRAYA, T. Effects of silver thiosulfate complex (STS) in combination with sucrose on the vase life of cut sweet pea flowers. Journal of the Japanese Society for Horticultural Science, Tokyo, v. 68, n. 1, p. 23-27, 1999.

ICHIMURA, K.; HISAMATSU, T. Effects of continuous treatment with sucrose on the vase life, soluble carbohydrate concentrations, and ethylene production of cut Snapdragon flowers. Journal of the Japanese Society for Horticultural Science, Tokyo, v. 68, n. 1, p. 61-66, 1999.

ICHIMURA, K.; SUTO, K. Effects of the time of sucrose treatment on vase life, soluble carbohydrate concentrations and ethylene production in cut sweet pea flowers. Plant Growth Regulation, Amsterdam, v. 28, n. 2, p. 117-122, 1999.

Pesq. agropec. bras., Brasília, v. 37, n. 8, p. 1065-1070, ago. 2002 
KOHL, H. C. Cyclamen as cut flowers. California: Flower Nurs, 1975. $60 \mathrm{p}$.

LORENZI, H.; SOUZA, H. Plantas ornamentais no Brasil. São Paulo: Plantarum, 1999. 1088 p.

MARKHART, A. H.; HARPER, M. S. Deleterious effects of sucrose in preservative solutions on leaves of cut roses. HortScience, Alexandria, v. 30, n. 7, p. 1429-1432, 1995.

NOWAK, J.; RUDNICKI, R. M. Postharvest handling and storage of cut flowers, florist greens, and potted plants. Portland: Timber, 1990. 210 p.

ROGERS, M. N. A historical and critical review of postharvest physiology research on cut flowers. HortScience, Alexandria, v. 8, p. 189-194, 1973.

SACALIS, J. N. Cut flowers prolonging freshness. 2. ed. Batavia: Ball, 1993. 110 p.
STIMART, D. P.; BROWN, D. J.; SOLOMOS, T. Development of flowers and changes in carbon dioxide, ethylene, and various sugars of cut Zinnia elegans Jacq. Journal of the American Society for Horticultural Science, Alexandria, v. 108, n. 4, p. 651-655, 1983.

WILLIAMSON, V. G.; MILBURN, J. A. Cavitation events in cut stems kept in water: implications for cut flower senescence. Scientia Horticulturae, Amsterdam, v. 64, p. 219-232, 1995.

WOLTERING, E. J.; DOORN, W. G. van. Role of ethylene in senescence of petals-morphological and taxonomical relationships. Journal of Experimental Botany, Oxford, v. 35 , p. 1605-1616, 1988.

YOUNG, H. C.; ONG, H. T. Effects of chemical applied to cut stalks on the shelf life on Oncidium Goldiana flowers. Orchid Reviews, v. 87, n. 1035, p. 292-295, 1979. 